\title{
Elasto-Magnetic Pumps Integrated within Microfluidic Devices ${ }^{\dagger}$
}

\author{
Jacob L. Binsley ${ }^{1, *}$, Elizabeth L. Martin ${ }^{1}$, Thomas O. Myers ${ }^{2}$, Stefano Pagliara ${ }^{3}$ and Feodor Y. Ogrin ${ }^{1}$ \\ 1 Department of Physics and Astronomy, University of Exeter, Physics Building, Stocker Road, \\ Exeter EX4 4QL, UK; em392@exeter.ac.uk (E.L.M.); f.y.ogrin@exeter.ac.uk (F.Y.O.) \\ 2 Platform Kinetics Limited, Pegholme, Wharfebank Mills, Otley LS21 3JP, UK; \\ tom.myers@platformkinetics.com \\ 3 Department of Biosciences, Living Systems Institute, University of Exeter, Stocker Road, \\ Exeter EX4 4QD, UK; s.pagliara@exeter.ac.uk \\ * Correspondence: jb778@exeter.ac.uk \\ † Presented at the 1st International Conference on Micromachines and Applications, 15-30 April 2021; \\ Available online: https://micromachines2021.sciforum.net/.
}

Citation: Binsley, J.L.; Martin, E.L.; Myers, T.O.; Pagliara, S.; Ogrin, F.Y. Elasto-Magnetic Pumps Integrated within Microfluidic Devices. Eng. Proc. 2021, 4, 48. https://doi.org/ 10.3390/Micromachines2021-09590

Academic Editor: Ion Stiharu

Published: 16 April 2021

Publisher's Note: MDPI stays neutral with regard to jurisdictional claims in published maps and institutional affiliations.

Copyright: $\odot 2021$ by the authors. Licensee MDPI, Basel, Switzerland. This article is an open access article distributed under the terms and conditions of the Creative Commons Attribution (CC BY) license (http://creativecommons.org/licenses/by/4.0/).

\begin{abstract}
Many lab-on-a-chip devices require a connection to an external pumping system in order to perform their function. While this is not problematic in typical laboratory environments, it is not always practical when applied to point-of-care testing, which is best utilized outside of the laboratory. Therefore, there has been a large amount of ongoing research into producing integrated microfluidic components capable of generating effective fluid flow from on-board the device. This research aims to introduce a system that can produce practical flow rates, and be easily fabricated and actuated using readily available techniques and materials. We show how an asymmetric elastomagnetic system, inspired by Purcell's three-link swimmer, can provide this solution through the generation of non-reciprocal motion in an enclosed environment. The device is fabricated monolithically within a microfluidic channel at the time of manufacture, and is actuated using a weak, oscillating magnetic field. The flow rate can be altered dynamically, and the direction of the resultant flow can be controlled by adjusting the frequency of the driving field. The device has been proven, experimentally and numerically, to operate effectively when applied to fluids with a range of viscosities. Such a device may be able to replace external pumping systems in portable applications.
\end{abstract}

Keywords: elasto-magnetic; microfluidic; lab-on-a-chip; pump

Supplementary Materials: The supplementary file is available online at https://www.mdpi.com/article/10.3390/Micromachines2021-09590/s1.

Institutional Review Board Statement: Not applicable.

Informed Consent Statement: Not applicable.

Data Availability Statement: This abstract is accompanied by a supporting paper which can be found here: https://doi.org/10.1039/D0LC00935K, with a dataset which can be found here: https://ore.exeter.ac.uk/repository/handle/10871/123693. 